\title{
Computação e Psicologia: Construindo uma Parceria Interdisciplinar para o Ensino de Computação em Escolas
}

\author{
Andrea Charão ${ }^{1}$, Francisco Ritter ${ }^{2}$, Christian Brackmann ${ }^{3}$, Ana Luísa Solórzano ${ }^{1}$ \\ Juliana Schneider ${ }^{2}$, Pâmela Schumann ${ }^{2}$ \\ ${ }^{1}$ Centro de Tecnologia \\ Universidade Federal de Santa Maria \\ ${ }^{2}$ Centro de Ciências Sociais e Humanas \\ Universidade Federal de Santa Maria \\ ${ }^{3}$ Instituto Federal Farroupilha
}

\begin{abstract}
The introduction of Computing fundamentals in primary and secondary education has been defended, mainly, by researchers and academics in Computing and Education. In this article, we propose to expand this field by developing an interdisciplinary partnership between Computing and Psychology, seeking benefits both for the school community and for the university community. For this, we discuss some references to build a common bibliography and we analyze curricular guidelines for undergraduate courses in Computing and Psychology. In addition, we present some joint actions articulating extension, teaching and research, organized around the theme of developing computational thinking in schools.
\end{abstract}

Resumo. A introdução de fundamentos de Computação na educação básica tem sido defendida, principalmente, por pesquisadores e acadêmicos com formações nas interfaces entre Computação e Educação. Neste artigo, propõe-se ampliar este campo com a construção de uma parceria interdisciplinar entre Computação e Psicologia, buscando benefícios tanto para a comunidade escolar como para a comunidade universitária. Para isso, discute-se referenciais que podem constituir uma base comum e analisa-se relações da Computação na formação superior em Psicologia e da Psicologia na formação superior em Computação. Além disso, apresenta-se algumas ações conjuntas articulando extensão, ensino e pesquisa, organizadas em torno do tema do desenvolvimento do pensamento computacional em escolas.

\section{Introdução}

A introdução de conceitos de Computação na educação básica é um tema bastante abordado atualmente, tanto em artigos acadêmicos [Bordini et al. 2016] como em notícias voltadas ao grande público [Stock 2017]. Recentemente, muitos países reformularam suas diretrizes curriculares da educação básica, propondo-se a desenvolver, desde cedo, noções sobre os fundamentos da computação entre crianças e jovens [Brackmann et al. 2016]. Ao mesmo tempo, proliferaram iniciativas de ensino não-formal de Computação, com grande oferta de programas, projetos e ferramentas que se propõem a estimular o desenvolvimento do pensamento computacional e o aprendizado de programação no público em idade escolar [Amaral et al. 2013]. 
Neste cenário, nota-se um grande envolvimento de pesquisadores e acadêmicos nas áreas de Computação e Educação, que exercem lideranças neste tema. Da intersecção entre estas áreas, formam-se profissionais já conscientes da tendência em inserir noções de Computação desde os primeiros níveis de ensino, visando preparar as novas gerações para a compreensão e a resolução de problemas complexos, em um mundo cada vez mais transformado por novas tecnologias [Leite et al. 2017].

Reconhece-se que as relações multi e interdisciplinares são importantes neste cenário, pelo seu potencial de alavancar abordagens e soluções inovadoras a desafios que se apresentam à sociedade moderna. Ainda assim, muitas experiências de inserção da Computação na educação básica são lideradas por equipes relativamente homogêneas, com forte presença de professores e acadêmicos com formação superior em Computação ou pós-graduação em Informática na Educação [Avila et al. 2016]. Isso fica evidente, por exemplo, ao observar-se as vinculações dos autores de artigos publicados em eventos como o Simpósio Brasileiro de Informática na Educação (SBIE), o Workshop de Educação em Computação (WEI), o Workshop de Informática na Escola (WIE) ou, mais recentemente, o Workshop de Ensino em Pensamento Computacional, Algoritmos e Programação (WAlgProg).

Neste artigo, apresenta-se um esforço de construção de uma parceria interdisciplinar, entre professores e estudantes de Computação e Psicologia de instituições de ensino superior, unidos para o desenvolvimento de ações de ensino não-formal de Computação junto a escolas. Por meio dessa parceria, tem-se como objetivo qualificar e aprimorar ações que já vinham sendo desenvolvidas isoladamente, bem como propiciar trocas e lançar novos olhares sobre questões de interesse comum.

O artigo está organizado da seguinte forma: nas seções 2, 3 e 4, busca-se construir referenciais em comum, iniciando por um assunto agregador - o Pensamento Computacional - e continuando com um olhar sobre a formação superior em Computação e em Psicologia no Brasil. Nesses referenciais, identificam-se espaços para as relações interdisciplinares em prol de ações na educação básica. Na seção 5, relata-se ações conjuntas desenvolvidas junto a um público de alunos de uma escola de ensino fundamental, com tutoria de graduandos em Computação e Psicologia. Na seção 6, apresenta-se um embrião de uma pesquisa exploratória que analisa jogos do Code.org à luz de teorias sobre desenvolvimento cognitivo. Por fim, na seção 7, apresentam-se considerações finais.

\section{Pensamento Computacional e Psicologia Cognitiva}

"O Pensamento Computacional se baseia no potencial dos processos de computação, sejam eles executados por humanos ou máquinas. Métodos computacionais e modelos nos dão a coragem de resolver problemas e desenhar sistemas que ninguém achou que fôssemos capazes."

Esse é o parágrafo de abertura do influente artigo "Pensamento Computacional" [Wing 2006], na época em que o interesse dos estudantes pelos cursos em Ciência da Computação havia caído ao nível mais baixo desde o seu surgimento. Enfatizando um termo já empregado por um importante precursor [Papert 1980], a autora repercutiu ao defender a importância do ensino de programação, que continua a ser atual ainda hoje: mais de dez anos depois, está claro para muitos o valor de se desenvolver desde cedo nas pessoas a capacidade de programar, para que deixem de ser meras consumidoras ingênuas 
VII Congresso Brasileiro de Informática na Educação (CBIE 2018)

Anais dos Workshops do VII Congresso Brasileiro de Informática na Educação (WCBIE 2018)

de produtos de computação e se tornem, elas mesmas, potenciais criadoras daquilo que necessitam ou têm desejo em termos de programas e aplicativos.

Por outro lado, a Psicologia tem demonstrado a necessidade humana de integração e adaptação ao meio, já que o que nos leva a agir é a constante busca por interação social [Dreyfus 1975]. Portanto, há uma ligação direta entre ensino de Computação (e desenvolvimento do Pensamento Computacional) e a Psicologia, em torno da preocupação com o fato de estarmos cada vez mais interagindo em um meio digital onde funciona a lógica da computação sem sermos capazes de entender e modificar este meio, o que nos leva a um estado de alienação.

Possuir conhecimentos de programação e ser capaz de pensar nos termos da Computação implica em se apropriar do meio em que o sujeito vive [Lakoff e Núñez 2000]. A Psicologia tem demonstrado que nós humanos não percebemos o ambiente diretamente; na verdade, definimos em grande parte a situação em que estamos. Um ambiente pode de fato existir, mas importante mesmo é a definição que damos do ambiente. A definição não acontece por acaso, ela resulta do pensamento e da interação social em andamento. Neste sentido, o ensino das formas de Pensamento Computacional é fundamental para que possamos fazer essa definição e, a partir dela, agir de forma consciente e autônoma nas plataformas digitais que fazem parte cada vez mais de nossas vidas.

Acima de tudo, é preciso entender que somos seres ativos em nossa relação com o ambiente [Bruner 2002]. A Psicologia tem demonstrado que estamos sempre ativamente envolvidos naquilo que fazemos; quando não estamos (seja por falta de oportunidade ou por impedimento) se desenvolvem em nós as diferentes patologias psíquicas, todas elas resultado de algum tipo de alienação do sujeito em relação ao meio em que realiza suas interações sociais.

Para a Psicologia, não existe um módulo central para a cognição. Todos os fenômenos cognitivos, incluindo aqueles considerados típicos da cognição amodal, como raciocínio, processamento numérico e da linguagem, são, em última análise, embasados em (e emergem de) uma variedade de processos afetivos, perceptuais e motores. O desenvolvimento da cognição é limitado pela corporeidade dos agentes cognitivos e por fatores contextuais variados nos quais estes agentes estão imersos (contextos físicos e sociais). A mente existe para preparar nosso próximo passo no mundo das interações sociais, e a moeda em circulação no cérebro é o sentido, não a informação. Por isso, o ensino do Pensamento Computacional, mais do que revelar as formas de pensamento humano, o que faz é dar ao sujeito uma habilidade e ferramentas efetivas para sua interação social. Com o Pensamento Computacional, o sujeito irá identificar mais facilmente a presença de objetivos compartilhados nas atividades em linguagem digital que envolvem colaboração, e isto é essencial para que ele possa refletir sobre o meio (digital) onde está interagindo e a forma como os outros o percebem neste meio.

\section{Formação superior em Psicologia e relações com a Computação}

As diretrizes curriculares nacionais para os cursos de Psicologia estão em processo de revisão por parte da categoria: a partir do fim de 2017, ocorreram reuniões em todo país com a finalidade de estabelecer novos rumos para a formação dos psicólogos e psicólogas, uma vez que o Conselho Nacional de Saúde verificou a necessidade de se promover uma atualização dos currículos, diante de uma nova conjuntura social e política no Brasil. Assim 
VII Congresso Brasileiro de Informática na Educação (CBIE 2018)

Anais dos Workshops do VII Congresso Brasileiro de Informática na Educação (WCBIE 2018)

é que, ao longo deste ano de 2018, ocorreram discussões coletivas a respeito do assunto e, em uma reunião promovida pelo Conselho Federal de Psicologia em julho, em Brasília, se elaborou a minuta que servirá de base para o documento final determinando as novas diretrizes curriculares que os cursos de graduação deverão seguir [CFP/ABEP/FENAPSI 2018].

Entre as ideias aprovadas está a de que o estudante de Psicologia deve se inserir, o quanto antes possível, em trabalhos que estejam estruturados em rede, ou seja, que os futuros psicólogos e psicólogas venham a vivenciar cedo em suas graduações uma realidade que é comum nos locais de exercício da profissão, especialmente no SUS: o trabalho interdisciplinar, colaborativo e em rede. Neste sentido, o Pensamento Computacional e o ensino de programação, que seriam objetos de estudo típicos da área da Computação, se tornam áreas nas quais a Psicologia pode - e deve - se interessar [Cardoso et al. 2018], já que são indispensáveis para a abordagem de uma série de fenômenos humanos que se articulam em rede, como a adolescência, por exemplo. A adolescência é um fenômeno humano que aparece tradicionalmente em todos currículos de graduação em Psicologia, mas como entendê-la sem levar em conta o envolvimento dos adolescentes com o mundo digital? A partir da constatação deste fato, vemos que somente o trabalho interdisciplinar entre Psicologia e Computação pode dar conta da integralidade do fenômeno.

No entanto, os currículos tradicionais de Psicologia não preveem esta abertura a outros saberes e formas de intervenção na realidade; é somente a partir de agora, com as novas diretrizes curriculares em Psicologia, que novos campos interdisciplinares ganharão espaço no interior dos cursos. Alguns conteúdos que já vêm sendo trabalhados mostram interfaces com a Ciência da Computação que podem facilitar a integração e o diálogo entre as áreas: na Psicologia do Desenvolvimento, temos o estudo da formação da inteligência feito por Jean Piaget; em Processos Psicológicos Básicos, a cognição humana é estudada em seus fundamentos; e com a Terapia Cognitivo Comportamental, se estuda a chamada "metáfora computacional" como modelo do funcionamento da mente [Piaget 1985]. Nestes casos, e em outros, se observa a facilidade com que Psicologia e Computação podem vir a formar um novo campo de estudo interdisciplinar; o Pensamento Computacional e o ensino de programação nas escolas são, em nossa opinião, o ponto de partida ideal para o início desta colaboração.

\section{Formação superior em Computação e relações com a Psicologia}

As diretrizes curriculares nacionais para a área de Computação [MEC/CNE/CES 2012] estabelecem o perfil dos egressos, suas competências e habilidades e os conteúdos curriculares para os cursos de bacharelado em Ciência da Computação, bacharelado em Engenharia da Computação, bacharelado em Sistemas de Informação, bacharelado em Engenharia de Software e licenciatura em Computação. Conforme consta no documento, tais diretrizes são resultado de um processo envolvendo consultas públicas e atuação de um grupo de trabalho com representantes da Sociedade Brasileira de Computação.

Nas referidas diretrizes, o perfil geral dos egressos dos cursos de bacharelado e licenciatura em Computação é caracterizado em uma lista de 8 itens. Nessa lista, há pelo menos 4 itens que relacionam-se fortemente com questões humanísticas e sociais, ao estabelecer que os cursos devem assegurar a formação de profissionais dotados: " $d o$ conhecimento das questões sociais, profissionais, legais, éticas, políticas e humanísticas", "da compreensão do impacto da computação e suas tecnologias na sociedade no que 
VII Congresso Brasileiro de Informática na Educação (CBIE 2018)

Anais dos Workshops do VII Congresso Brasileiro de Informática na Educação (WCBIE 2018)

concerne ao atendimento e à antecipação estratégica das necessidades da sociedade", "da capacidade de atuar de forma empreendedora, abrangente e cooperativa no atendimento às demandas sociais da região onde atua, do Brasil e do mundo" e "da capacidade de reconhecer a importância do pensamento computacional na vida cotidiana, como também sua aplicação em outros domínios e ser capaz de aplicá-lo em circunstâncias apropriadas".

No que diz respeito aos conteúdos curriculares da formação tecnológica e básica para todos os cursos de bacharelado e de licenciatura, tem-se um conjunto de 48 conteúdos que podem ser selecionados para compor os projetos pedagógicos, complementados pelos conteúdos específicos de cada formação na área de Computação. No conjunto de conteúdos comuns a todos os cursos, observa-se que apenas uma pequena parcela relacionase diretamente a questões humanísticas e sociais, a saber: "interação humano-computador; ética e legislação; empreendedorismo; computação e sociedade; filosofia; fundamentos de administração; fundamentos de economia". A interação humano-computador, em particular, é um campo que prosperou na interface entre Computação e Psicologia.

Já nos conteúdos curriculares específicos a cada formação, as relações com questões humanísticas e sociais ficam mais evidentes para os cursos de bacharelado em Engenharia de Software, bacharelado em Sistemas de Informação e licenciatura em Computação. Notase, para estes cursos, alguns conteúdos fortemente relacionados com os objetos de estudo da Psicologia, a saber: no bacharelado em Engenharia de Software, "relações humanas de trabalho; dinâmica e psicologia de grupo; impactos sociais da tecnologia de software"; no bacharelado em Sistemas de Informação, "psicologia aplicada a sistemas de informação;" e na licenciatura em Computação, "modelagem cognitiva aplicada à educação; psicologia da aprendizagem".

Cursos de licenciatura em Computação possuem, naturalmente, interfaces com conteúdos de formação pedagógica e devem considerar Diretrizes Curriculares Nacionais para a formação de professores para a Educação Básica. Com um viés de pesquisa, programas de pós-graduação em Informática na Educação também têm abordado questões relativas à introdução da Computação ao público em idade escolar. Assim, é natural que muitas iniciativas brasileiras nesse tema tenham como protagonistas professores, pesquisadores e estudantes vinculados a esses cursos de graduação e pós-graduação. Resta, no entanto, uma pergunta que se soma a inquietações similares [Jonathan 2016]: como se espera que os egressos dos demais cursos também reforcem sua formação humanística e social, se os conteúdos de natureza inter ou multidisciplinar são tão pouco representados nos currículos?

Nessa direção, há que se considerar que, além dos conteúdos obrigatórios, as diretrizes reconhecem as atividades complementares como componentes curriculares capazes de 'enriquecer e expandir o perfil do egresso com atividades que privilegiem aspectos diversos da sua formação". Neste item, atividades de extensão universitária junto à comunidade, ou de ensino em programas de tutoria, podem se alinhar com a formação humanística e social dos egressos. Em particular, atividades complementares têm grande potencial para reunir pessoas com diferentes formações em trabalhos pluri, multi, inter ou transdisciplinares, uma vez que ocorrem habitualmente fora do ambiente delimitado pelas matrículas e salas de aula das instituições de ensino superior. 
VII Congresso Brasileiro de Informática na Educação (CBIE 2018)

Anais dos Workshops do VII Congresso Brasileiro de Informática na Educação (WCBIE 2018)

\section{Ações Conjuntas com o Público-Alvo}

A parceria interdisciplinar entre Computação e Psicologia, objeto deste artigo, iniciou em um programa de extensão vinculado a uma instituição pública de ensino superior. Este programa, em desenvolvimento há alguns anos, articula diferentes projetos que disseminam e exploram os fundamentos da Computação junto a alunos e professores da educação básica, no município de Santa Maria (RS) e região [Charão et al. 2015].

Pela interação dialógica entre a universidade e as escolas, o programa desenvolve atividades com recursos variados, sempre envolvendo estudantes de graduação em Ciência da Computação e Sistemas de Informação, que participam tanto do planejamento como da tutoria das atividades junto à comunidade de alunos e professores das escolas. Dentre alguns recursos utilizados, estão jogos do Code. $\operatorname{org}^{1}$ e atividades de computação desplugada [Bell et al. 2015].

Embora obtivesse resultados alinhados com seus objetivos extensionistas, o programa não levava em conta, por exemplo, seu impacto sobre o desenvolvimento cognitivo dos participantes. Isso motivou, no início de 2018, um professor e duas estudantes do curso de bacharelado em Psicologia a se tornaram colaboradores do programa, agregando subsídios da teoria construtivista de Jean Piaget ao planejamento e execução das atividades.

Após encontros de formação e planejamento entre docentes e graduandos, foram realizados 2 encontros de 4 horas com a comunidade de uma escola municipal de ensino fundamental, participante do programa. As atividades foram oferecidas na universidade em sábados, fora do período de aulas, para alunos e professores de diferentes turmas, do $5^{\circ}$ ao $9^{\circ}$ ano, indicados pela coordenação pedagógica e direção da escola. Ao todo, participaram 24 alunos com idades entre 9 e 12 anos e 10 professores. Após uma explanação inicial sobre as atividades, o público alternou-se entre o uso de jogos do Code.org em laboratório e atividades de computação desplugada. Os jogos do Code.org utilizados foram o "Labirinto Clássico" e "O Artista". As atividades de computação desplugada foram adaptadas da seção "Kidbots" do site CS Unplugged: nessas atividades, há sempre um ou vários "robôs" (tutores, crianças ou grupos) que devem ser programados para atingir algum objetivo (por exemplo, chegar em um determinado ponto em um espaço pré-definido). Essas atividades se relacionam diretamente com os desafios do Code.org escolhidos.

Uma equipe de 9 graduandos dos cursos da área de Computação (tutores) apresentou as atividades e acompanhou sua realização, prestando o auxílio necessário, enquanto estudantes do curso de Psicologia atentavam para os aspectos cognitivos e relacionais dos alunos participantes durante o processo de aprendizagem. Todos os participantes, tanto alunos como professores, conseguiram concluir as etapas do jogo Labirinto Clássico do Code.org, alguns com mais facilidade que outros. Na sequência, alguns resolveram outro desafio, denominado Artista. Para acompanhar o progresso dos participantes, utilizou-se a área de professores no Code.org. Coletou-se também opiniões dos professores, que ressaltaram como ponto forte a alternância entre atividades desplugadas e em laboratório.

Nos encontros realizados, verificou-se a validade da abordagem de Jean Piaget também no desenvolvimento de noções de programação entre as crianças e jovens. No ensino de programação, é muito útil estudar a cognição humana e entender que ela se desenvolve em etapas lógicas sucessivas, para que os professores saibam qual conteúdo

\footnotetext{
${ }^{1}$ http://code.org
} 
cada aluno está pronto para receber e entendam as razões das dificuldades de aprendizagem que eles têm. A partir dos resultados, observou-se que a participação da Psicologia e a reflexão sobre o desenvolvimento cognitivo que ela trouxe ao projeto foram de grande importância. O desenvolvimento do pensamento computacional através de uma metodologia construtivista foi muito bem aceito pelos estudantes e professores, e programas desta natureza têm todas condições para serem implantados em outras escolas com o mesmo perfil que a escola em que este projeto foi implantado.

A experiência de observação participativa com estudantes de Psicologia também permitiu identificar oportunidades de melhoria nas ações dos tutores junto aos alunos:

- Considerando que as atividades com a comunidade da escola são esporádicas, é difícil que tutores e participantes se tratem pelos seus nomes, embora isso seja desejável para incentivar um tratamento personalizado dos envolvidos. Para contornar esse problema, sugeriu-se o uso de crachás, além da chamada inicial que já era feita.

- Como o progresso nos jogos do Code.org ocorre no ritmo de cada aluno, e como alguns alunos progridem rapidamente e interagem mais com os tutores, notou-se que é comum os graduandos dedicarem atenção a quem mostra ter mais facilidade, quando o contrário deveria ser a regra. Para lidar com isso, é importante que os tutores estejam atentos a alunos que progridem lentamente ou não buscam auxílio. Além disso, os tutores podem incentivar alunos com melhor desempenho a auxiliarem seus colegas.

- Entre os tutores, é comum que alguns poucos sejam mais desinibidos que outros e desempenhem papeis de liderança, centralizando a atenção dos alunos e fornecendo orientações a todo grupo nos momentos apropriados, enquanto outros fiquem mais à vontade atuando no auxílio individual aos alunos. No entanto, é importante que os graduandos exercitem diferentes habilidades (liderança, comunicação, etc.), o que pode ser obtido com uma rotatividade de papeis junto ao público-alvo.

\section{Ações Conjuntas em Pesquisa Exploratória}

A partir da obra de Jean Piaget, analisou-se os jogos propostos no Code.org que foram utilizados em encontros com as crianças do ensino fundamental, levando em conta as 5 operações que estão por trás de todo processo cognitivo, a saber: de-centração, conservação, classificação, seriação e reversibilidade. A seguir explora-se cada uma delas sucintamente, junto com a análise dos jogos do Code.org.

A conservação (ou conservação do objeto) é a operação que caracteriza o início do pensamento simbólico em si, ou seja, uma criança que consegue realizá-la indica, com isso, que já manipula mentalmente representações simbólicas dos objetos do meio ambiente (aí incluídos seus familiares). A criança que possui a conservação consegue afirmar a identidade de um objeto mesmo depois de este ter sofrido alguma mudança na aparência, e o faz porque já possui um registro simbólico daquele objeto que a permite reconhecê-lo como sendo o mesmo apesar da aparência modificada. Estas representações mentais são a matéria prima do pensamento inteligente e da capacidade de formar e testar hipóteses. No caso dos desafios do Code.org, a alternância com atividades desplugadas ajuda muito no desenvolvimento da conservação, já que as peças e tabuleiro dos jogos são reais e permitem a manipulação física, facilitando a transição do raciocínio para o plano puramente simbólico, abstrato. 
Com a classificação, a criança consegue ampliar a eficiência deste espaço simbólico na medida em que diferentes representações de objetos são agrupadas sob uma mesma categoria e diferenciadas de outros objetos que pertencem a outra categoria. Já há aí a presença de manipulação mental de símbolos, pois os objetos representados podem passar de uma categoria para outra segundo o desejo da criança, sem importar as características reais dos objetos (por exemplo, a representação mental de "elefante" pode sair da categoria "animais pesados" e ser levada para a categoria "animais que começam com a letra e", sem que isso represente um problema).

Tendo dominado a conservação e a classificação, a criança está habilitada a ampliar ainda mais a complexidade de seu raciocínio através da operação de seriação. Nela, a criança entende que há "lugares" logicamente necessários dentro dos conjuntos, e que cada representação ocupa um lugar somente em relação às outras representações no mesmo conjunto. Há, portanto, caminhos necessários para o raciocínio, que passa a ser cada vez mais dedutivo. Esta é a base do pensamento em algoritmos, ou árvores de tomada de decisão. No caso dos exercícios do Code.org, nota-se que esta operação é desenvolvida através de desafios que, para serem superados, necessitam ser desdobrados em sequências de ações. Estes desafios são apresentados de forma lúdica, bastante semelhante ao que se encontra nos jogos que as crianças já conhecem e gostam.

Quando a criança está bem habituada a realizar operações de seriação, é possível surgir a operação de reversibilidade, através da qual ela percebe que pode seguir o raciocínio pelos caminhos logicamente necessários, mas não só no sentido da conclusão. É possível também retornar sobre os próprios passos para testar caminhos diferentes e reiniciar a partir de pontos anteriormente trilhados, só que agora em direção de conclusões distintas. Com a reversibilidade, o pensamento vai e volta, até que a criança encontre a conclusão que lhe parece resolver o problema que lhe foi colocado. Nos exercícios do Code.org, a reversibilidade aparece como pré-requisito para a solução dos problemas, pois sem ela o sujeito não sabe como desfazer a estratégia equivocada através do reconhecimento do ponto onde começou a errar. Para além disso, verificou-se que, na sequência de códigos utilizados que os exercícios apresentam ao longo do problema (e que a criança pode examinar à vontade, para adiante e para trás, até achar o ponto onde tomou a decisão que gerou o resultado errado), há um estímulo à aquisição da noção de reversibilidade e ao surgimento do raciocínio hipotético dedutível, puramente lógico e independente das características dos objetos envolvidos no problema.

Por último, é importante lembrar da operação de de-centração, que permite ao sujeito ocupar pontos de vista distintos do seu e examinar problemas podendo mudar o contexto que condiciona sua leitura; por exemplo: uma situação é apresentada a uma criança e ela não se assusta, mas se perguntamos para ela o que teria acontecido se a mesma situação tivesse sido apresentada a uma criança menor, ela é capaz de dizer que esta se assustaria. A de-centração é, portanto, uma operação distinta das outras, porque envolve o próprio lugar do sujeito diante do problema; sem estar de-centrado, ninguém consegue avançar em qualquer análise que se apresente. Nos exercícios do Code.org, a de-centração aparece o tempo todo, na medida em que é preciso que a criança enxergue o problema pelos olhos do avatar que a representa no jogo; por exemplo, se o avatar já dobrou à direita, o próximo comando de dobrar à direita significa uma mudança de rumo diferente para a criança, que verá o avatar completar uma meia volta. Para entender isso, é necessário 
VII Congresso Brasileiro de Informática na Educação (CBIE 2018)

Anais dos Workshops do VII Congresso Brasileiro de Informática na Educação (WCBIE 2018)

um determinado nível de maturidade que crianças pequenas não possuem. Neste sentido, reitera-se a importância das atividades desplugadas, que permitem o desenvolvimento gradual, por tentativa e erro, desta capacidade.

\section{Considerações Finais}

Neste artigo, apresentou-se aspectos da construção de uma parceria interdisciplinar entre docentes e graduandos das áreas de Computação e Psicologia, que uniram esforços para o desenvolvimento de ações de ensino não-formal de Computação junto a escolas. A partir de referenciais e de motivações compartilhados, foram desenvolvidas ações articulando ensino, extensão e pesquisa, beneficiando não só um público externo ao meio universitário, mas também a equipe que as desenvolveu.

Para a comunidade escolar, a parceria interdisciplinar oferece olhares diversos para potencializar as experiências que disseminam noções de Computação a este público. Para graduandos em Computação e Psicologia, acredita-se que o desenvolvimento do Pensamento Computacional e o ensino de programação em escolas seja um terreno bastante fértil e desafiador. Trata-se de um tema agregador que complementa os conteúdos curriculares de ambas as formações, podendo ter um impacto profundo nas novas gerações de egressos.

Uma tal parceria interdisciplinar, por si só, já é desafiadora por exigir convergência de interesses, agendas e linguagens. Ao apresentarmos um olhar sobre o Pensamento Computacional e sobre os currículos de Computação e Psicologia, identificamos termos, motivações e espaços para esta convergência. Reunimos, sucintamente em um mesmo texto, considerações para que profissionais de cada área se reconheçam e conheçam mais uns sobre os outros, a partir de seus objetos de estudo. Assim, acredita-se que os referenciais e experiências deste trabalho possam alavancar a replicação e ampliação deste tipo de parceria em outras instituições. Especificamente em nosso grupo, pretende-se ampliar as ações interdisciplinares junto a outras escolas abrangidas pelo programa, criando novas oportunidades de crescimento mútuo.

\section{Referências}

Amaral, H. J., França, R. S., e Silva, W. C. (2013). Despertando o interesse pela ciência da computação: práticas na educação básica. In Proceedings of the VIII International Conference on Engineering and Science Education, pages 284-288.

Avila, C., Bordini, A., Marques, M., Cavalheiro, S., e Foss, L. (2016). Desdobramentos do Pensamento Computacional no Brasil. In Anais do XXVII Simpósio Brasileiro de Informática na Educação (SBIE 2016).

Bell, T., Witten, I. H., e Fellows, M. (2015). CS unplugged: An enrichment and extension programme for primary-aged students. Disponível em: https://classic.csunplugged.org.

Bordini, A., Avila, C. M. O., Weisshahn, Y., da Cunha, M. M., da Costa Cavalheiro, S. A., Foss, L., Aguiar, M. S., e Reiser, R. H. S. (2016). Computação na educação básica no Brasil: o estado da arte. Revista de Informática Teórica e Aplicada, 23(2):210-238.

Brackmann, C., Barone, D., Casali, A., Boucinha, R., e Muñoz-Hernandez, S. (2016). Computational thinking: Panorama of the americas. In 2016 International Symposium on Computers in Education (SIIE), pages 1-6. 
VII Congresso Brasileiro de Informática na Educação (CBIE 2018)

Anais dos Workshops do VII Congresso Brasileiro de Informática na Educação (WCBIE 2018)

Bruner, J. (2002). Realidade mental, mundos possíveis. Artmed, Porto Alegre.

Cardoso, R. M., Filho, H. B. N., e de Freitas, L. A. B. (2018). Ensino e pesquisa no século XXI: Um manifesto pelo ensino de programação na graduação em Psicologia, chapter 9. Associação Brasileira de Psicologia e Medicina Comportamental, Campinas, São Paulo.

CFP/ABEP/FENAPSI (2018). Repensando a formação do(a) psicólogo(a): revisão das diretrizes curriculares nacionais para os cursos de graduação em Psicologia. Disponível em: http://site.cfp.org.br/wp-content/uploads/2018/01/cartilha-Ano-da-Forma

Charão, A., Barcelos, P. P., de Azevedo, B. R., e Lima, J. C. (2015). Clube de computação para alunos de ensino médio: um relato de experiência. In Anais do XXIII Workshop sobre Educação em Computação.

Dreyfus, H. (1975). O que os computadores não podem fazer. Eldorado, Rio de Janeiro.

Jonathan, M. (2016). Currículos de Computação: por que permanecem assim? In Anais do XXIV Workshop sobre Educação em Computação.

Lakoff, G. e Núñez, R. (2000). Where mathematics comes from: how the embodied mind brings mathematics into being. Basic Books, New York.

Leite, M., Reinaldo, F., Maschio, E., Marczal, D., e Oliveira, C. M. (2017). Pensamento Computacional nas Escolas: Limitado pela Tecnologia, Infraestrutura ou Prática Docente? In Anais do III Workshop de Ensino em Pensamento Computacional, Algoritmos e Programação (WAlgProg 2017).

MEC/CNE/CES (2012). Diretrizes curriculares nacionais para os cursos de graduação em computação. Parecer CNE/CES no. 136/2012. Disponível em: http://portal.mec.gov.br/component/content/article?id=12991.

Papert, S. (1980). Mindstorms: Children, Computers, and Powerful Ideas. Basic Books, Inc., New York, NY, USA.

Piaget, J. (1985). As formas elementares da dialética. Casa do Psicólogo, São Paulo.

Stock, A. (2017). Linguagens de programação para crianças: como ajudar seus filhos a escapar do "analfabetismo do futuro". BBC Brasil. Disponível em: https://www.bbc.com/portuguese/geral-42145774.

Wing, J. M. (2006). Computational thinking. Commun. ACM, 49(3):33-35. 